\title{
Multidimensional dependency subgroups in community-dwelling older adults: A latent class analysis
}

\author{
Subgrupos de dependencia multidimensional en adultos mayores \\ que viven en la comunidad: un análisis de clase latente
}

\author{
Kely Rely ${ }^{1}$; Delfino-Vargas-Chanes ${ }^{1}$; Carmen García-Peña ${ }^{2}$; Guillermo Salinas-Escudero ${ }^{3}$; \\ Luis-Miguel Gutiérrez-Robledo ${ }^{4}$; Rebeca Wong ${ }^{5}$
}

\begin{abstract}
Suggested citation: Rely K, Vargas-Chanes D, García-Peña C, Salinas-Escudero G, Gutiérrez-Robledo LM, Wong R. Multidimensional dependency subgroups in community-dwelling older adults: A latent class analysis. Salud UIS. 2020; 52(2): 101-109. doi: http://dx.doi.org/10.18273/revsal.v52n2-2020004 (c) (1)
\end{abstract}

\begin{abstract}
Objectives: Use latent class analysis (LCA) to identify patterns of multidimensional dependency in a sample of older adults and assess sociodemographic, predictors of class membership. Material and methods: Longitudinal data were used from the Mexican Health and Aging Study (MHAS). 7,920 older adults, 55\% women, were recruited. LCA were used to identify meaningful subgroups. LCA was conducted using MPlus version. The final class model was chosen based on the comparison of multiple fit statistics and theoretical parsimony, with models of increasing complexity analyzed sequentially until the best fitting model was identified. Covariates were incorporated to explore the association between these variables and class membership. Results: Three classes groups based on the nine indicators were identified: "Active older adults" was comprised of $64 \%$ of the sample participants, "Relatively independent" and "Physically impaired" were comprised of $26 \%$ and $10 \%$ of the sample. The "Active older adults" profile comprised the majority of respondents who exhibited high endorsement rates across all criteria. The profiles of the "Active older adults" and "Relatively independent" were comparatively more uniform. Finally, respondents belonging to the "Physically impaired" profile, the smallest subgroup, encompassed the individuals most susceptible to a poor dependency profile. Conclusions: These findings highlighted the usefulness to adopt a person-centered approach rather than a variable-centered approach, suggesting directions for future research and tailored interventions approaches to older adults with particular characteristics. Based on patterns of multidimensional dependency, this study identified a typology of dependency using data from a large, nationally representative survey.
\end{abstract}

Keywords: Multidimensional dependency; Latent class analysis; Ageing; MHAS.

1. Universidad Nacional Autónoma de México. México City.

2. Instituto Nacional de Geriatría. México City.

3. Hospital Infantil de México Federico Gómez, México City.

4. Instituto Nacional de Geriatría, México City.

5. University of Texas Medical Branch, USA.

Correspondence: Delfino Vargas-Chanes. Address: Programa Universitario de Estudios de Desarrollo Universidad Nacional Autónoma de México Av. Universidad 3000, Ciudad Universitaria Alcaldía de Coyoacán, 04510 Ciudad de México, CDMX. Phone number: +52 1551695 6208.Email:dvchanes@gmail.com. 


\section{Resumen}

Objetivo: Utilizar el análisis de clase latente (ACL) para la identificación de patrones de dependencia multidimensional en una muestra de adultos mayores y evaluar factores sociodemográficos predictivos de pertenencia a una clase. Métodos: Se utilizaron datos longitudinales del Estudio Nacional de Salud y Envejecimiento en México (ENASEM). Se analizaron 7,920 adultos mayores, el 55\% eran mujeres. El ACL fue utilizado para la identificación de subgrupos significativos. Para el ACL se realizó con el software MPlus. El modelo de clase final se eligió con base a la comparativa de estadísticas de ajuste múltiple y parsimonia teórica, con modelos de complejidad creciente analizados secuencialmente hasta que se identificó el modelo de mejor ajuste. Se incorporaron covariables para explorar la asociación entre estas variables y la pertenencia a clases. Resultados: Se identificaron tres grupos de clases basados en los nueve identificadores. "Adultos mayores activos" estaba compuesto por el $64 \%$. "Relativamente independiente" y "Discapacidad física" comprenden el $26 \%$ y el 10\% de la muestra, respectivamente. Los perfiles de "Adultos mayores activos" y "Relativamente independiente" eran comparativamente más uniformes. El grupo de "discapacidad física" comprenden a los individuos más propensos a un perfil de dependencia. Conclusiones: Estos hallazgos resaltan la utilidad de adoptar un enfoque centrado en la persona lo que sugiere nuevos horizontes de investigación e intervención a medida de las características particulares de los adultos mayores. Basado en patrones de dependencia multidimensional, este estudio identificó una tipología de dependencia utilizando datos de una encuesta representativa a nivel nacional.

Palabras clave: Dependencia multidimensional; Análisis de clases latente; Envejecimiento; ENASEM.

\section{Introduction}

Globally, the population is growing older and has major socioeconomic consequence of increasing importance, and pose major challenges for the health care system and other areas of social policy. The number of older adults aged 60 years or over will increase by $56 \%$ between 2015 and 2030 and the population over 80 years of age (oldest-old) will increase even faster ${ }^{1-3}$.

In Mexico, the proportion of persons over the age of 60 has increased steadily in recent decades. According to the National Population Council (CONAPO), the percent of population aged 60 and older is expected to grow steadily, from $6 \%$ in 2000 , to $15 \%$ in $2027^{4}$. The country has experienced not only a reduction in the fertility rate in recent decades, but also a decline in premature mortality and an increase in life expectancy at birth $^{5,6}$. The average age of the Mexican population will increase from 27 to 30 years in this decade, and later, between 2030 and 2050, it will go from 38 to 45. Simultaneously, the population 65 and over will increase from 4.8 million to 17 million between 2000 and 2030, reaching about 32.5 million in the year 2050. This means that while today one out of every 20 Mexicans is an older adult, in 2030, one out of every eight will be and in 2050, one out of every four ${ }^{7,8}$.

Population aging has contributed to rising chronic disease and disability prevalence, growing demands on health and long-term care delivery systems, and pressing concerns regarding the sustainability of healthcare entitlement programs ${ }^{9-11}$. According to the ENSANUT $201247.8 \%$ of all adults ages 65 or older in the Mexico have chronic disabling conditions, and about $26.8 \%$ have serious mobility limitations ${ }^{12,13}$. Among adults in this same age group who do not perceive themselves as disabled, $3.2 \%$ are unable to perform at least one "activity of daily living" (ADL), and another 2.4 percent have difficulty performing at least one $\mathrm{ADL}^{13-15}$.

People experience dependency transitions during the aging process ${ }^{4,16}$. The dependency status of each older adult is a synergistic combination of multiple health dimensions. In addition, older adults might experience dependency transitions differently in regards to rate (quantity) and pattern (quality) of changes; that is heterogeneity ${ }^{17,18}$. Using any single health indicator to examine dependency change is insufficient to describe the complexity and heterogeneity of dependency transition completely. We postulated that for each condition there would be considerable heterogeneity in the dependency at the end of life.

In this research, we aim to answer the question, is whether there exists a latent classification that makes substantive sense to study the dynamic of dependence status in older populations presenting with complex care needs. We hypothesize that dependency in older adults is a multidimensional concept. This research identifies subgroup of multidimensional dependency, constructed on the basis of not only functional limitations but also social, psychological and economic domain. 


\section{Material and Methods}

For this study we performed a secondary dataanalysis on the MHAS, a longitudinal survey with a broad socioeconomic and health perspective. MHAS is the largest and longest running study on aging in Mexico. The MHAS began in 2001 with a nationally representative sample of 15,186 people aged 50 and older (response rate: 91.8\%). All persons aged at least 50 in the selected households were interviewed. Although the partners of eligible persons living in the same household were also surveyed independently of the age, we retained the sample aged 50 or above. Follow-up interviews were completed in 2003, 2012 and 2015. The third wave "2012" included a new group of individuals who participated in the survey for the first time. We use data from the third wave "2012". Detailed information about the survey is provided elsewhere?

\section{Inclusion criteria}

The current study is a secondary data analysis of variables from wave 2012 from the MHAS. Participants were included in the study sample if they (a) were present in wave 2012 survey $(n=7,920)$.

The present study used four major dependency domains to measure multidimensional dependency patterns: physical, social, psychological and economic. These four variables were observed at 2012. Therefore, a total of nine indicators were used to measure multidimensional dependency.

\section{Latent class analysis}

This study employed LCA to identify classes of dependency in Mexican older adults. LCA is widely assessed in the psychology medical, economic, and social research, where heterogeneous populations constitute the focus of analysis. In geriatric, LCA has been used heterogeneity of health of the elderly to test criterion validity of physical frailty ${ }^{19}$, measure mobility disability ${ }^{20}$ and study behavioral syndromes in Alzheimer' patients ${ }^{21}$. We found no example of its use to model heterogeneity in older individuals' multidependency. LCA provides an empirical method that examines the interrelationships among sociodemographic indicators and characterizes the underlying set of mutually exclusive latent classes that account for the observed indicators. To elucidate the heterogeneity within elderly people, we have explored the physical, psychological social and economic domains of dependency. We have conceptualized dependency from a broader perspective, which also includes the psychological social and economic domains ${ }^{22-24}$. Still, the distinction between the separate domains does not demonstrate the full complexity of dependency in older people. The domains might influence or reinforce each other and thus it remains unclear which specific combinations lead to adverse outcomes ${ }^{25}$. The observed variables we used in the LCA were Physical functioning (ADL, IADL, and vision impairment, difficulties flights of stairs, difficulties pushing or pulling), social functioning (marital status), psychological functioning (depressive symptoms, cognitive impairment) and economic distress Table 1.

Table 1. Sample characteristics at 2012, The Mexican Health and Aging Study (MHAS).

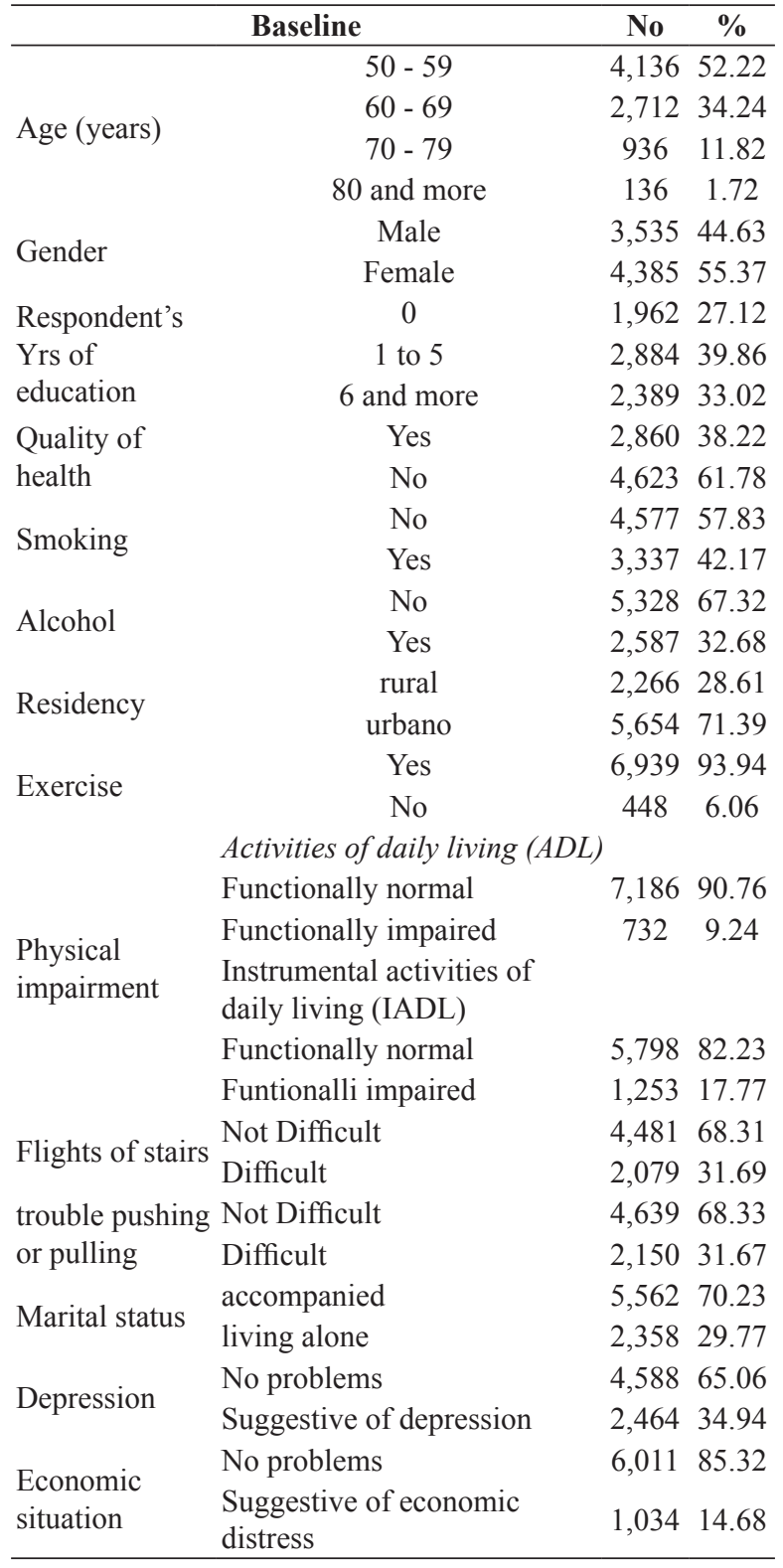




\section{Physical dimension}

In this study, physical functioning was assessed with two commonly used measures of functional status: activities of daily living ${ }^{26}$, instrumental activities of daily living ${ }^{27}$. These scales are based on Likert-type self-reports of the difficulty involved in walking, bathing, eating, dressing, moving from bed to chair, and using the toilet (activities of daily living); cooking, shopping, doing housework, using the telephone, and managing money (independent activities of daily living). In this study, those reporting difficulty or inability to carry out two or more of the six ADL were defined as having a dependence. Participants were asked how much difficulty they had performing those activities from 0 (completely independent) to 3 (unable to do the activity at all). Sum scores of personal ADL and IADL were calculated and then averaged to obtain an overall functional limitation score.

The limitations in physical functioning were similarly measured for the following activities: climbing a flight of stairs without pausing, and pushing or hauling large objects such as living room furniture.

\section{Vision impairment}

Vision quality was assessed by two self-reported indicators: distance eyesight and reading eyesight with the usual use of glasses or contact lenses. Subjects who considered that their eyesight was fair or poor and not excellent, very good, or good, were categorized as visually impaired.

\section{Social dimension}

Widowhood is a situation that may coexist with economic, social, and psychological problems, as well as changes in health behaviors and functional disability due to health problems derived from widowhood and emotional stress ${ }^{28}$, which in turn can lead to depression ${ }^{29,30}$. Widowhood was assessed with the question "What is your current marital status?" Response options were dichotomized: single, married, civil union, divorced, or separated were coded as " 0 " and widowed as " 1 ".

\section{Psychological dimension}

Depression symptoms is assessed with the Centers for Epidemiologic Studies Depression (CES-D) scale st. $^{31}$ The CES-D scale was developed by the Center for Epidemiologic Studies at the National Institute of Mental Health for use in studies of depression in community samples. The CES-D have 8 items and has been used in studies of elderly population. The scale contains eight dichotomous items "yes/no responses" reflecting a respondent's feelings much of the time over the week prior to the interview (a) depressed, (b) that everything they did was an effort, (c) their sleep was restless, (d) unhappy, (e) lonely, (f) they did not enjoy life, or (g) sad. We reverse-coded the positive items to construct a summary score (range 0-7), with higher scores indicating more pronounced depressive symptoms. A response with a value of 1 is considered positive for depressive symptoms.

\section{Cognitive impairment}

Global cognitive function was assessed by the modified version of the short version of the Cross-Cultural Cognitive Examination (CCCE), which focuses on the epidemiological and cross-cultural evaluation of cognitive functioning status. The domains of executive functioning, visual learning and memory, verbal learning and memory, working memory, expressive language, visual spatial functioning, and information processing speed were assessed using a variety of measures with adequate reliability and validity, as outlined below. The individual measures were scored based on available age-matched normative data, with the resulting scaled scores for each test utilized as the units of analysis to better assess patterns across tasks and within domains.

Memory problems have two subdimensions, namely immediate memory and delayed memory. We evaluated verbal memory (learning and recall, scores from 0 to 8), visuo-constructive skills (copying a figure and recalling that figure, scores from 0 to 8 ), and visual scanning (scores from 0 to 60 ). The maximum score for the cognitive scales used is 88 points.

The participants' cognitive functioning status was estimated using five cognitive domains, each including five items: verbal learning (immediate recall of an 8 -word list), verbal memory (delayed recall of an 8 -word list), visual-constructive skills (drawing of two figures in 90 seconds), visual memory (delayed recall of the figures previously drawn), and attention (visual scanning). Immediate memory was evaluated by asking respondents to recall a list of 10 words. After performing this and other cognitive performance tests, the subjects were asked to recall all the words they could from the initial word list, this time to assess delayed memory. Based on the results of the cognitive assessments we divided subjects into two groups, those (a) with normal cognitive abilities and (b) those with impaired cognitive 
abilities. We evaluated verbal memory (learning and recall, scores from 0 to 8), visuo-constructive skills (copying a figure and recalling that figure, scores from 0 to 8 ), and visual scanning (scores from 0 to 60 ). The maximum score for the cognitive scales used is 88 points. Standardized normative scores for each measure were calculated. Raw scores for all measures were converted to standardized scores ( $Z$ scores) and then assigned to their corresponding raw scores with a mean of 0 and a standard deviation of 1 . We made a total score variable that included all components. This scale was reverse scored to construct a scale for memory issues (the higher the score, the greater the memory problems).

\section{Economic dimension}

The question was asked: "How is the economic situation of your family?" and answers included the following categories: excellent, very good, good, fair, or poor. The answer "poor" was indicative of economic distress. The categories were combined and coded as follows: $1=$ (poor), 0 = (fair, good, very good, or excellent).

\section{Explanatory Variables}

We tested the relation between sociodemographic covariates and class membership profile ${ }^{32,33}$. Three groups of covariates were used to predict multidimensional dependency patterns, including demographic, social and health-related behavioral factors ${ }^{34}$. The demographic factors were age (50 - 59, 60 - 69, 70 - 79, 80 - more), sex (male, female), and education ( 0,1 to 5,6 and more) level. The social factors included quality of life (excellent or very good, very poor), place of residence (urban, rural), and exercise (health improve with exercise, no). The variables constituting health-related behavioral factors included alcohol use and tobacco use. All of the covariates were time-independent.

\section{Data analysis}

We used LCA classify individuals into distinctive and theoretically meaningful subgroups/classes that represent particular response patterns of multiple categorical indicators in the complex array of data $^{35,36}$. We assume that individuals weigh aspects of dependency differently and attempts to analyze empirical patterns based on similarities in dependency items via person-centered analysis ${ }^{33,37}$. This approach formulates categorical latent variables that represent underlying concepts of dependency based on observable multiple indicators ${ }^{38}$.
Five statistical obtained with LCA, Aka1ke Information Criteria AIC, Bayesian Information Criterion (BIC), Entropy, Lo-Mendell-Rubin (LMR) and Lo-MendellRubin likelihood ratio test (aLMRLRT) which combine goodness of fit and parsimony ${ }^{35,39}$. The adjusted LoMendell-Rubin likelihood ratio test (aLMRLRT) used to decide on the number of classes $^{40}$; it compares improvement in fit $(\mathrm{p}<0.001)$ between sequential class models through an approximation of the LRT distribution. The Entropy is used to assess how well the model predicts class membership; values range from 0 to 1 and high values are preferred ${ }^{41,42}$.

\section{Results}

The total study population consisted of 7,920 older people. Of the respondents, who ranged in age from 51 to 105 years old at the baseline, about $52 \%$ were between 50 and 59 years old, 34\% were between 60 and 69 years old, and $2 \%$ were 80 year old or older. The sample was nearly evenly split by gender $(55 \%$ female). While $27 \%$ of the respondents had zero years of education and about $40 \%$ have between 1 to 5 years of education, around $33 \%$ or 6 and more year of education. Overall, the sample reported higher levels of ADL (90\%) and IADL (82\%) respectively. In contrast, relatively low economic independence was found (15\%). The descriptive statistics of each variable at both waves are presented in Table 1.

The models were fit with an increasing number of class sizes until the best sample adjusted value was reached. Four statistics obtained with LCA, the AIC, BIC, entropy and the BLRT, have been found to be the most effective at identifying the number of latent classes that should be extracted from the indicator variables, and fourth criteria were considered in selecting from among the four different LCA solutions for each of these constructs. With the AIC, BIC, the solution with the smallest value is identified as the optimal model, whereas the BLRT tests the statistical significance of the improvement in the model when an additional class is extracted.

The lowest AIC and BIC value reached for the 4-class model but larger LMR-LR test p-value was statistically significant for the 4-class model $(\mathrm{p}<0.053)$ indicated that the 3-class model should not be rejected in favor of the 4-class model. Classification quality, based upon the average conditional probabilities for most likely class membership, indicated that the three classes were reasonably well defined: 0.93 for latent class one, and 0.94 for latent class three. The entropy measure $(0.65)$ 
similarly suggested that the data was adequately defined by a three-class solution. The bottom panel in Table
2 reports the structure matrix for the three-class LCA solution for the dependency items.

Table 2. Model fit values and statistical test results for the fitted mixture models.

\begin{tabular}{cccccccc}
\hline Class & AIC & BIC & Entropy & Class count and proportion & Probability & LMR test & LMR adjusted \\
\hline 1 & 57154 & 57184 & & & & & \\
2 & 52763 & 52828 & 0.72 & $0.28-0.72$ & $0.90-0.93$ & $\mathrm{p}<0.000$ & 4354. \\
3 & 52384 & 52482 & 0.65 & $0.10-0.64$ & $0.67-0.94$ & $\mathrm{p}<0.000$ & 393 \\
4 & 52265 & 52398 & 0.64 & $0.11-0.64$ & $0.66-0.85$ & $\mathrm{p}<0.053$ & 135 \\
\hline
\end{tabular}

Note: $\mathrm{AIC}=$ Akake Information Criteria; LMR $=$ Lo-Mendell-Rubin (LMR) likelihood ratio test, BIC $=$ Bayesian Information Criterion. A smaller BIC value suggests a better model fit. Entropy values range from zero to one, with values closer to one indicating clearer delineation of latent classes. Reported p-values are for LMR-adjusted log ratio test.

The item-response probabilities together provide a sense of what characterizes the three different dependency profiles these older adults. Unconditional item probabilities of class- 1 and class- 2 trended consistent, the class-1 was labeled "Active older adults" because individuals in this status had the highest probability of independence in all observed indicators. Individuals in the class-2 labeled "Relatively independent" had a high probability of independency in all observed indicators. Finally, participants in Class III had a distinct dependency profile compared to the Class I and
II participants. Members of the Class III had probability of independency in all observed indicators. We labeled this class the "Physically impaired".

The estimated unconditional probability of each class of endorsing or reporting each item was shown in Table 3. The unconditional probability of "active older adults" was 0.64 . This means that "Active older adults" was comprised of $64 \%$ of the sample participants. The "Relatively independent" and "Physically impaired" were comprised of $26 \%$ and $10 \%$ of the sample.

Table 3. Average Posterior Probabilities for a three-class model.

\begin{tabular}{|c|c|c|c|}
\hline & $\begin{array}{l}\text { Active older adults } \\
\quad(n=5,034,64 \%)\end{array}$ & $\begin{array}{l}\text { Relatively independent } \\
\quad(n=2,059,26 \%)\end{array}$ & $\begin{array}{c}\text { Physically impaired } \\
(\mathrm{n}=827, \mathbf{1 0} \%)\end{array}$ \\
\hline Independence in ADL & 0.996 & 0.96 & 0.312 \\
\hline Independence in IADL & 0.951 & 0.771 & 0.1 \\
\hline Without vision impairment & 0.954 & 0.855 & 0.738 \\
\hline Without difficulties flights of stairs & 0.918 & 0.376 & 0.053 \\
\hline Without difficulties pushing or pulling & 0.923 & 0.363 & 0.104 \\
\hline Marital status & 0.777 & 0.646 & 0.475 \\
\hline Without depressive symptoms & 0.82 & 0.414 & 0.333 \\
\hline Without cognitive imparment & 0.948 & 0.928 & 0.91 \\
\hline Economic independence & 0.917 & 0.77 & 0.714 \\
\hline
\end{tabular}

\section{Multinomial Logistic regression}

We performed multinomial logistic regression tests to compare each pair of classes (based on pseudoclass draws from posterior probability-based class membership) in terms of differences in each demographic characteristic. Participants in "Relatively independent" were significantly more likely to be older $(\mathrm{OR}=1.04 ; \mathrm{p}=.001)$, have Excellent or very good OofL
$(\mathrm{OR}=2.17 ; \mathrm{p}=.001)$, were significantly less likely to be male $(\mathrm{OR}=.53 ; \mathrm{p}=.001)$ compared with participants in the "Active older adults" profile.

"Physically impaired" differed from class "Active older adults" profile in that "Physically impaired" participants were significantly more likely to be older $(\mathrm{OR}=1.15$; $\mathrm{p}=.001)$ and less likely to be male $(\mathrm{OR}=.39 ; \mathrm{p}=.001)$. (Table 4) 
Table 4. Odds ratios (95\% Confidence intervals) of the association between predictors and latent class membership (Reference "Active older adults" group).

\begin{tabular}{|c|c|c|c|c|c|c|}
\hline & \multicolumn{3}{|c|}{ Relatively independent } & \multicolumn{3}{|c|}{ Physically impaired } \\
\hline & OR & $\mathbf{P}>\mid \mathbf{z}$ & IC $95 \%$ & OR & $\mathbf{P}>\mid \mathbf{z}$ & IC $95 \%$ \\
\hline Age in years & 1.04 & 0.000 & $\left(\begin{array}{ll}1.03 & 1.05\end{array}\right)$ & 1.15 & 0.000 & $\left(\begin{array}{ll}1.13 & 1.16\end{array}\right)$ \\
\hline Sex [Male] & 0.53 & 0.000 & $\left(\begin{array}{ll}0.47 & 0.61\end{array}\right)$ & 0.39 & 0.000 & $\left(\begin{array}{ll}0.32 & 0.48\end{array}\right)$ \\
\hline Education in years [0 year education] & 0.93 & 0.000 & $\left(\begin{array}{ll}0.92 & 0.95\end{array}\right)$ & 0.96 & 0.002 & $\left(\begin{array}{ll}0.94 & 0.98\end{array}\right)$ \\
\hline Quality of life [Excellent or very good] & 2.17 & 0.000 & $\left(\begin{array}{ll}1.92 & 2.45\end{array}\right)$ & 3.05 & 0.000 & $(2.493 .75)$ \\
\hline Cigarette smoking [Not regularly] & 1.10 & 0.124 & $\left(\begin{array}{ll}0.97 & 1.25\end{array}\right)$ & 1.16 & 0.131 & $\left(\begin{array}{ll}0.96 & 1.40\end{array}\right)$ \\
\hline Alcohol use [Not regularly] & 0.91 & 0.154 & $\left(\begin{array}{ll}0.80 & 1.04\end{array}\right)$ & 0.76 & 0.013 & $\left(\begin{array}{ll}0.61 & 0.94\end{array}\right)$ \\
\hline County rurality [Rural] & 1.02 & 0.727 & $\left(\begin{array}{ll}0.90 & 1.16\end{array}\right)$ & 1.07 & 0.484 & $\left(\begin{array}{ll}0.88 & 1.30\end{array}\right)$ \\
\hline Exercise [Health improve exercise] & 1.27 & 0.032 & $\left(\begin{array}{ll}1.02 & 1.59\end{array}\right)$ & 0.96 & 0.824 & $\left(\begin{array}{ll}0.69 & 1.35\end{array}\right)$ \\
\hline
\end{tabular}

\section{Discussion}

This study not only examines the multidimensional dependency profile using a longitudinal panel in a Mexican older adult. We identified the characteristics of elderly people by exploring their multidimensional dependency profiles and the sociodemographic characteristics of these profiles. Three classes groups based on the nine indicators were identified: "Active older adults", "Relatively independent" and "Physically impaired". The "Active older adults" profile comprised the majority of respondents who exhibited high endorsement rates across all criteria. The profiles of the "Active older adults" and "Relatively independent" were comparatively more uniform. Finally, respondents belonging to the "Physically impaired" profile, the smallest subgroup, encompassed the individuals most susceptible to a poor dependency profile. We found that older age, being female, and lower socioeconomic status increased the risk of membership of the "Physically impaired" group as compared to the "Active older adult" group. Being in the older age groups increased the risk of being in the "Physically impaired" group. The participants in these groups have a greater probability of being physically impaired, having more psychological impairment, and possessing fewer assets. Also, they were older, were predominantly female, had less schooling, and had poorer QOL compared with the participants in the other groups. This dependency pattern was generally related to physical dependency, which agrees with the finding that managing medical conditions was the prevalent task engaged in by this group.

It has been well documented that the heterogeneous group of older adults actually consumes a large and sometimes inappropriate share of health care services ${ }^{32}$. The results of this research illustrates that elderly persons in the "Physically impaired" profile report more functional and economic problems than "Active older adults" and "Relatively independent" profile. Results of this study expresses obviously that the prevalence of dependency is very high in this groups. The explanation behind this phenomenon is the late age and weakening body in the final segment of life. Older persons with sufficient economic/financial resources can fulfill their needs of daily life appropriately. ${ }^{32}$ From this perspective, the approach of assessing the effects of heterogeneity and exploring their sociodemographic characteristics could be used by decision makers to understand health characteristics of older adults, to project their subsequent care needs and adjust the distribution of health care resources.

To our knowledge, this is the first investigation to examine the multidimensional dependency, specific domains of dependency physical, social, psychological and economic using latent class statistical methods. The underlying principle of latent class analysis is to search for an unobserved latent categorical variable that explains the association among a set of observed variables. The latent class model has two advantages. First, the model does not demand that we assign older adults to a specific class, as each elderly receives an estimated probability of class membership. In other words, misclassification error is minimized. Second, the latent class model also lets us, simultaneously, take into account baseline covariates other than the key variables under study in assessing their independent relationship to dependency membership class.

\section{Strengths and Limitations}

The current study has a number of strengths. It used LCA to identify individual subgroups of multidimensional dependency and to delineate intergroup differences that were based on dependency alone rather than mixing them with other health 
condition indices. Then, it (independently) explored the association of multidimensional dependency profiles with sociodemographic covariates.

Multidimensional dependency is a very complex approach. The use of LCA to group older adults into a limited number of subgroups with similar combinations of latent dependency variable is much more practical than analysis of every possible variable combination. Therefore, we performed LCA based on the hypothesis that the dependency is a multidimensional construct. In this study, we used a LCA to identify probabilistic rather than deterministic subgroups based on responses to a set of observed variables, and assumes that the pattern is explained by unobserved categorical latent variables of $\mathrm{K}$ classes.

\section{Conclusions}

This study identified three qualitatively separate, broad multidimensional dependency using LCA in a Mexican nationally representative sample of older adults with distinct Physical, social, psychological, economic and sociodemographic characteristics. The latent classes identified presented relatively low misclassification errors, and demonstrated predictive and external validity. Multidimensional dependency has been consistently related to greater burden and increased use of health services. The single-indicator paradigm does not seem to fit the majority of persons with more than one dependency condition. Future efforts should focus on the underlying mechanisms of these multidimensional dependency clusters (Physical, social, psychological, economic) and determine targets for prevention and intervention.

\section{Conflict of interests}

The authors declare that they have no Financial and Non-financial competing interests.

\section{References}

1. United Nations. Department of International Economic and Social Affairs. Population D. World Population Ageing; 2013.

2. Coale AJ, Hoover EM. Population growth and economic development: Princeton University Press; 2015.

3. Mirkin B, Weinberger MB. The demography of population ageing. publicado en Population Bulletin of the United Nations. 2001; 42(43): 37-53.
4. Angel JL, Vega W, López-Ortega M. Aging in Mexico: Population trends and emerging issues. Gerontologist. 2017; 57(2): 153-162. doi: 10.1093/ geront/gnw136.

5. Frenk J, Bobadilla JL, Stern C, Frejka T, Lozano R. Elements for a theory of the health transition. Health Transit Rev. 1991; 1(1): 21-38.

6. Frenk J, Sepúlveda J, Gómez-Dantés O, Knaul F. Evidence-based health policy: three generations of reform in Mexico. Lancet. 2003; 362(9396): 16671671. doi: 10.1016/S0140-6736(03)14803-9.

7. Wong R, Michaels-Obregon A, Palloni A. Cohort Profile: The Mexican Health and Aging Study (MHAS). Int J Epidemiol. 2015: dyu263.

8. Wong R, Palloni A. Aging in Mexico and Latin America. International handbook of population aging: Springer; 2009. p. 231-252.

9. Murillo-López S, Venegas-Martínez F. Cobertura de los sistemas de pensiones y factores asociados al acceso a una pensión de jubilación en México. Pap Poblac 2011; 17(67): 209-250.

10. Robledo LMG, Campos RHM, Ortega ML. Present State of Elder Care in Mexico. Challenges of Latino Aging in the Americas: Springer; 2015. p. 379-392.

11. García-Peña C, Wagner FA, Sánchez-Garcia S, Juárez-Cedillo T, Espinel-Bermúdez C, GarcíaGonzalez JJ, et al. Depressive symptoms among older adults in Mexico City. J Gen Intern Med. 2008; 23(12): 1973-1980. doi: 10.1007/s11606008-0799-2.

12. Gutierrez JP, Rivera-Dommarco J, Shamah-Levy T, Villalpando-Hernández S, Franco A, Cuevas-Nasu $\mathrm{L}$, et al. Encuesta nacional de salud y nutrición 2012. Resultados Nacionales Cuernavaca, México: Inst Nacional de Salud Pública. 2012.

13. Gutiérrez-Robledo LMF, García-Peña MdC, Jiménez-Bolón JE. Envejecimiento y dependencia. Realidades y previsión para los próximos años Intersistemas, editor. México: Intersistemas; 2014.

14. Gerst K, Michaels-Obregon A, Wong R. The impact of physical activity on disability incidence among older adults in Mexico and the United States. J Aging Res. 2011; 2011: 420714. doi: 10.4061/2011/420714.

15. Wong R, Gerst K, Michaels-Obregon A, Palloni A. Burden of Aging in developing countries: disability transitions in Mexico compared to the United States. Manuscript submitted for publication. 2010.

16. Doubova SV, Pérez-Cuevas R, Espinosa-Alarcón P, Flores-Hernández S. Social network types and functional dependency in older adults in Mexico. BMC Public Health. 2010; 10(1): 104. 
17. Angel RJ, Angel JL, Lee G-Y, Markides KS. Age at migration and family dependency among older Mexican immigrants: Recent evidence from the Mexican American EPESE. The Gerontologist. 1999;39(1):59-65.

18. Angel RJ, Angel JL, Hill TD. Subjective control and health among Mexican-origin elders in Mexico and the United States: Structural considerations in comparative research. J Gerontol B Psychol Sci Soc Sci. 2009; 64B(3): 390-401. doi: 10.1093/ geronb/gbn029.

19. Bandeen-Roche K, Xue Q-L, Ferrucci L, Walston J, Guralnik JM, Chaves P, et al. Phenotype of frailty: characterization in the women $>$ s health and aging studies. The J Gerontol A: Biol Sci Med Sci. 2006; 61(3): 262-266. doi: 10.1093/gerona/61.3.262.

20. Bandeen-Roche K, Miglioretti DL, Zeger SL, Rathouz PJ. Latent variable regression for multiple discrete outcomes. J Am Statistical Association. 1997; 92(440): 1375-1386. doi: https://doi.org/10.1 080/01621459.1997.10473658.

21. Moran M, Walsh C, Lynch A, Coen RF, Coakley D, Lawlor BA. Syndromes of behavioural and psychological symptoms in mild Alzheimer's disease. Int J Geriatr Psychiatry. 2004; 19(4): 359364. doi: 10.1002/gps.1091.

22. Robledo LMG. La salud del anciano en México y la nueva epidemiología del envejecimiento. 2004.

23. Gutiérrez-Robledo LMF, García-Peña MdC, Jiménez-Bolón JE. Envejecimiento y dependencia. Realidades y previsión para los próximos años. México: Intersistemas; 2014.

24. Barrantes-Monge M, García-Mayo EJ, GutiérrezRobledo LM, Miguel-Jaimes A. Dependencia funcional y enfermedades crónicas en ancianos mexicanos. Salud Pública Méx. 2007; 49(s4): S59-S66.

25. Aguilar-Navarro SG, Amieva H, Gutiérrez-Robledo LM, Avila-Funes JA. Frailty among Mexican community-dwelling elderly: a story told 11 years later. The Mexican health and aging study. Salud Pública Mex. 2015; 57(Supp 1): s62-s9.

26. Katz S, Ford AB, Moskowitz RW, Jackson BA, Jaffe MW. Studies of illness in the aged: the index of ADL: a standardized measure of biological and psychosocial function. JAMA. 1963; 185(12): 914919. doi: 10.1001/jama.1963.03060120024016.

27. Lawton MP, Brody EM. Assessment of older people: self-maintaining and instrumental activities of daily living. Nursing Research. 1970; 19(3): 278.

28. Harwood RH, Sayer AA, Hirschfeld M. Current and future worldwide prevalence of dependency, its relationship to total population, and dependency ratios. Bull World Health Organ. 2004; 82(4): 251-258.

29. Isherwood LM, King DS, Luszcz MA. A longitudinal analysis of social engagement in latelife widowhood. Int J Aging Hum Dev. 2012; 74(3): 211-229. doi: https://doi.org/10.2190/AG.74.3.c.

30. Donnelly EA, Hinterlong JE. Changes in social participation and volunteer activity among recently widowed older adults. Gerontologist. 2009; 50(2): 158-169. doi: 10.1093/geront/gnp103.

31. Radloff LS. The CES-D scale a self-report depression scale for research in the general population. Applied psychological measurement. 1977; 1(3): 385-401.

32. Lafortune L, Béland F, Bergman H, Ankri J. Health state profiles and service utilization in communityliving elderly. Med Care. 2009; 47(3): 286-294. doi: 10.1097/MLR.0b013e3181894293.

33. Muthén BO. Beyond SEM: General latent variable modeling. Behaviormetrika. 2002; 29(1): 81-117.

34. Dorantes-Mendoza G, Avila-Funes JA, MejiaArango S, Gutierrez-Robledo LM. Factors associated with functional dependence in older adults: a secondary analysis of the National Study on Health and Aging, Mexico, 2001. Rev Panam Salud Publica 2007; 22(1): 1-11. doi: 10.1590/ s1020-49892007000600001.

35. Magidson J, Vermunt J. Latent class models for clustering: A comparison with K-means. Canadian J Marketing Res. 2002; 20(1): 36-43.

36. Reboussin BA, Liang KY, Reboussin DM. Estimating equations for a latent transit ion model with multiple discrete indicators. Biometrics. 1999; 55(3): 839845. doi: 10.1111/j.0006-341x.1999.00839.x.

37. Muthén B, Muthén LK. Integrating person-centered and variable-centered analyses: Growth mixture modeling with latent trajectory classes. Alcohol Clin Exp Res. 2000; 24(6): 882-891.

38. McLachlan G, Peel D. Finite mixture models: John Wiley \& Sons; 2004.

39. Vermunt JK, Magidson J. Latent class cluster analysis. Applied latent class analysis. Edited by: Hagenaars JA, McCutcheon AL. 2002. Cambridge, UK: Cambridge University Press.

40. Lo Y, Mendell NR, Rubin DB. Testing the number of components in a normal mixture. Biometrika. 2001; 88(3): 767-778. doi: https://doi.org/10.1093/ biomet/88.3.767.

41. Schwarz G. Estimating the dimension of a model. Ann Statist. 1978; 6(2): 461-464.

42. Sclove SL. Application of model-selection criteria to some problems in multivariate analysis. Psychometrika. 1987; 52(3): 333-343. 